\title{
Catalytic Conversion of Residual Palm Oil in Spent Bleaching Earth (SBE) by HZSM-5 Zeolite based- Catalysts
}

\author{
Mohd Lukman Musa, Ramli Mat*, Tuan Amran Tuan Abdullah \\ Faculty of Chemical and Energy Engineering, Universiti Teknologi Malaysia, 81310 UTM Skudai, \\ Johor Bahru, Malaysia
}

Received: $10^{\text {th }}$ December 2017; Revised: $31^{\text {st }}$ May 2018; Accepted: $10^{\text {th }}$ June 2018; Available online: $14^{\text {th }}$ November 2018; Published regularly: December 2018

\begin{abstract}
Bleaching earth is used to remove colour, phospholipids, oxidized products, metals and residual gums in the palm oil process refinery. Once adsorption process end, the spent bleaching earth (SBE) which contains approximately $20-40 \mathrm{wt}$. \% of the adsorbed oil was usually disposed to landfills. The oil content in SBE was recovered by catalytic cracking using transition metal $(\mathrm{Cu}, \mathrm{Zn}, \mathrm{Cr}$, and $\mathrm{Ni})$ doped HZSM- 5 zeolite in a batch reactor (pyrolysis zone) and fixed bed reactor (catalyst bed). The 5 wt. $\%$ of each metallic was introduced in HZSM-5 zeolite using incipient wetness impregnation method. The main objective of this study was to investigate the performance of modified HZSM-5 zeolite for cracking of residual oil in SBE. The physicochemical properties of the catalysts were characterized using XRD, FTIR, Nitrogen adsorption, and TPD- $\mathrm{NH}_{3}$. Liquid biofuel obtained from cracking was analyzed by GC-MS. The incorporation of metallic loaded on HZSM- 5 zeolite has reduced the surface area of the catalyst that gives a significant impact to the catalytic behavior. The Ni/HZSM-5 zeolite exhibited the highest yields of alkenes as compared to others but slightly decreases the yield of alkanes whereas in contrast with the Cr/HZSM-5, the obtained alkanes were found higher than that of alkenes. In addition, the Cr/HZSM-5 and Ni/HZSM-5 favored the conversion of polycyclic aromatics to monoaromatics, whereas parent HZSM- 5 catalyst favored the formation of poly-aromatics. These results indicated that the metal loaded on HZSM- 5 can promote the cracking of heavy fractions to lighter hydrocarbon thus can be used for cracking oil in SBE. Copyright (C) 2018 BCREC Group. All rights reserved
\end{abstract}

Keywords: Palm Oil; Spent Bleaching Earth; Catalytic Cracking; Zeolite HZSM-5

How to Cite: Musa, M.L., Mat, R., Abdullah, T.A.T. (2018). Catalytic Conversion of Residual Palm Oil in Spent Bleaching Earth (SBE) By HZSM-5 Zeolite based-Catalysts. Bulletin of Chemical Reaction Engineering \& Catalysis, 13 (3): 456-465 (doi:10.9767/bcrec.13.3.1929.456-465)

Permalink/DOI: https://doi.org/10.9767/bcrec.13.3.1929.456-465

\section{Introduction}

Spent bleaching earth (SBE) is an industrial waste, mainly generated from the edible oil processing. It is noted that SBE can present a fire hazard (i.e. spontaneous combustion), because it usually contains $20-40$ wt. \% oil [1]. These oils

\footnotetext{
* Corresponding Author.

E-mail: ramli@cheme.utm.my (R. Mat)

Telp: +6(07) 553 5507, Fax: +6(07) 553616
}

retained and not removed by filter pressing may possess the pyrogenic nature due to the unsaturation. The waste is commonly disposed to landfill without any pretreatment. From the environmental, safe and regulatory points of view, it is suggested to restrict the landfill practice in the future.

During the refining process, $0.5-1.0 \%$ of activated clay or fresh bleaching earth (BE) is used which all of BE will convert into waste as SBE [2]. As the second largest producer of crude 
palm oil in the world, Malaysia alone produces more than 100,000 tonnes of SBE yearly which contains a high percentage of oil [3]. It is predicted that the production of SBE waste around the world is 600,000 tonne [2].

The recent study showed that pyrolysis of residue palm oil in SBE or non-edible vegetable oil has the potential to produce both chemical and fuel [4]. Boey et al. [3] reported that carboxylic acids ranging from $\mathrm{C}_{9}-\mathrm{C}_{18}$ and alkanes were the major classes of compounds found in the pyrolytic products analyzed using GC-MS. It shows that overall the major compound found in the pyrolysis product of residual palm oil in SBE was an $n$-hexadecanoic acid with a mixture of aliphatic and aromatic hydrocarbons composed of oxygenated components. Significant amounts of monoaromatic compounds, alkenes, alcohols, ketones, aldehydes, esters, nitrogenated compounds, and polycyclic aromatic hydrocarbons (PAHs) were found in the bio-oil produced in this study.

It is evident that liquid mixtures with high percentages of hydrocarbons can be obtained but in many of these studies undesirable, oxygenated compounds such as carboxylic acids and ketones still exist [5]. The major drawbacks of the bio-oil as fuel from pyrolysis is that it is highly oxygenated, viscous, corrosive and thermally unstable [6,7], while its high concentration of water and oxygenated compounds reduce its calorific value and change significantly the combustion characteristics. The presence of certain undesirable oxygenated compounds (organic acids and carbonyls) and of polycyclic aromatic hydrocarbons (PAH), limits its potential for direct use in engines or turbines [8]. The claims by these authors were similar results found by Boey et al. [3] whereby n-hexadecanoic acid was the major oxygenated compound found in SBE pyrolysis product compound.

Due to these problems, catalytic cracking of oil in SBE using HZSM-5 zeolite as a catalyst is introduced to enhance the production of biofuel which is expected to increase the amount of aromatic hydrocarbon and decrease amount oxygenated compounds. Catalysis plays important role in enhancing the yield of biofuel. In catalytic cracking processes the large triglyceride molecules are subjected to deoxygenation, being converted into a relatively broad range of hydrocarbons according to a variety of reaction pathways, which are determined by both operating conditions and the properties of the catalysts [9]. Among the different products that can be obtained, light olefins and aromatic hydrocarbons are particularly interesting due to their applications in the production of both raw chemicals and fuels [10].

Zeolite HZSM-5 is well known as an efficient catalyst for the conversion of petroleum based fuels due to its crystallinity, well-defined micropores, large surface area, interconnected network of channels, strong acidity and high resistance to deactivation. However, the chemical characteristics of vegetable oils are markedly different from those of petroleum oil. The relative narrow channels of zeolites lead to diffusional limitations and hinder the access to active catalytic sites for large reactants molecules such as triglycerides. To overcome these inconveniences, nanocrystalline zeolites have been extensively considered due to the high proportion of fully accessible catalytic sites located on the external surface [10]. The addition of transition metal compounds to a catalyst is expected to modify the acid and textural properties of the support changing its catalytic behavior [11]. The combination of metal centers with the zeolite acid sites leads to bifunctional catalysts. The activity and selectivity of the metal-modified zeolites is determined by critical parameters like the metal site location and the metallic diffusion and sintering [10].

The aim of this study is to investigate the performance of modified zeolite for cracking of residual oil in SBE. To achieve the objective, a set of HZSM-5 zeolite catalysts were impregnated with the different types of metals Zinc (Zn), Nickel (Ni), Copper (Cu), and Chromium (Cr). Up to date, no literature dedicated to an investigation of the catalytic cracking of residual palm oil in SBE by using HZSM-5 zeolite based catalyst has been reported. Cracking of palm oil has been carried out by Achmad Roesyadi et al. [12]. They recommend Ni/HZSM-5 catalyst for cracking palm oil for the high selectivity to gasoline.

\section{Materials and Method}

\subsection{Materials of Research}

Spent bleaching earth (SBE) containing up to 20 wt. \% of crude palm oil was obtained from palm oil refinery (Sime Darby Sdn. Bhd., Pasir Gudang, Johor, Malaysia). Zeolite HZSM-5 $\left(\mathrm{SiO}_{2} / \mathrm{nAl}_{2} \mathrm{O}_{3}=30\right)$ was obtained from Zeolyst, USA in solid powder form. Other chemicals substance used are copper nitrate $\left(\mathrm{CuN}_{2} \mathrm{O}_{6} .3 \mathrm{H}_{2} \mathrm{O}, 99.10 \%\right.$ purity), Zznk nitrate $\left(\mathrm{N}_{2} \mathrm{O}_{6} \mathrm{Zn} .6 \mathrm{H}_{2} \mathrm{O}, \geq 99.0 \%\right.$ purity), chromium ni- 
trate $\left(\mathrm{Cr}\left(\mathrm{NO}_{3}\right)_{3} .9 \mathrm{H}_{2} \mathrm{O}, \geq 99.99 \%\right.$ purity) and nickel nitrate $\left(\mathrm{N}_{2} \mathrm{NiO}_{6} \cdot 6 \mathrm{H}_{2} \mathrm{O}, \geq 97.0 \%\right.$ purity). These substances were purchased from by Sigma Aldrich (M) Sd. Bhd.

\subsection{SBE Themogravimetric (TGA) Analysis}

Thermogravimetric (Perkin Elmer, TGA) was used to study the decomposition temperature of the SBE before pyrolysis using the batch reactor. The measurements were carried out from 30 to $900{ }^{\circ} \mathrm{C}$ with a heating rate of 10 ${ }^{\circ}$ C.min ${ }^{-1}$ under nitrogen flow rate of $25 \mathrm{~mL}$. $\min ^{-1}$. The measurement was carried out in the air and the weight was recorded as a function of increasing temperature.

\subsection{Catalyst Preparation}

Each metal-loaded into HZSM-5 catalyst was prepared according to the wetimpregnation method. Initially, the parent HZSM-5 zeolite was added into $100 \mathrm{~mL}$ of distilled water. All metal nitrates in their solid state was then added into the solution, mixed and stirred at temperature $60-70{ }^{\circ} \mathrm{C}$ for an hour to make up a composition of $5 \mathrm{wt}$. \% metal $(\mathrm{Cu}$, $\mathrm{Zn}, \mathrm{Cr}$, and Ni) in HZSM-5 catalyst. The solution was then dried at $100{ }^{\circ} \mathrm{C}$ for $12 \mathrm{~h}$ and finally calcined at $550{ }^{\circ} \mathrm{C}$ for $5 \mathrm{~h}$. The calcined catalysts were then crushed and sieved between 40 and 50 mesh $(0.420 \mathrm{~mm}$ and $0.297 \mathrm{~mm})$ for a uniform catalyst size.

\subsection{Catalyst Characterization}

X-ray diffraction (XRD) was performed using Siemens Diffractometer D5000 (Software Diffract Plus) with $\mathrm{Cu}-\mathrm{Ka}$ radiation, $\lambda=$ $1.54056 \AA$ at $40 \mathrm{kV}$ and $30 \mathrm{~mA}$ in the range of $2 \theta=5^{\circ}-100^{\circ}$ at a screening speed of $0.05 \%$, with a vertical goniometer at room temperature (20 $\left.{ }^{\circ} \mathrm{C}\right)$.

The existence of impregnated metal in zeolite catalyst was analyzed by Fourier Transform Infra-Red (FTIR) analyzer. Infrared measurements were performed on a Perkin Elmer Spectrum One FTIR spectrometer, with a spectral resolution of $2 \mathrm{~cm}^{-1}$ the scan time of $10 \mathrm{~s}$ using the $\mathrm{KBr}$ pellet technique. The sample about $0.25 \mathrm{mg}$ of modified catalyst powder was mixed with $300 \mathrm{mg}$ of spectro grade $\mathrm{KBr}$ powder. Then, placed it on a die, pressed and pelletized using a hydraulic press. The range of 4000-370 $\mathrm{cm}^{-1}$ of IR spectra was recorded at room temperature.

Textural properties were measured using nitrogen adsorption-desorption isotherms at $-196{ }^{\circ} \mathrm{C}$ with a Micromeritics Autochem II
Chemisorption Analyzer instrument. Prior to the analyses, the samples were treated at 300 ${ }^{\circ} \mathrm{C}$ for $5 \mathrm{~h}$ under nitrogen flow in order to remove adsorbed compounds [10]. The BrunauerEmmet-Teller (BET) equation was used for specific surface area calculation, whereas the micropore volume was determined by the BJH. Barrett-Joyner-Halenda (BJH) adsorptiondesorption method [13].

The acidity of the catalyst was determined by Thermo Scientific temperature-programmed desorption of ammonia (TPD- $\mathrm{NH}_{3}$ ) in a fixedbed continuous flow micro-reactor at atmospheric pressure employing at the thermal conductive detector (TCD). The samples (0.1 g) were dried at $200{ }^{\circ} \mathrm{C}$ for $1 \mathrm{~h}$, and then $10 \%$ ammonia/90\% helium in an $\mathrm{NH}_{3}$ stream at $60{ }^{\circ} \mathrm{C}$ for $0.5 \mathrm{~h}$. After purging with helium (30 $\mathrm{mL} / \mathrm{min}$ ) at $60{ }^{\circ} \mathrm{C}$ for $0.5 \mathrm{~h}$ to remove the physically adsorbed $\mathrm{NH}_{3}$, the samples were heated at a linear heating rate of $20{ }^{\circ} \mathrm{C} / \mathrm{min}$ up to 650 ${ }^{\circ} \mathrm{C}$. In order to determine the acidity from the $\mathrm{NH}_{3}$ desorption profiles, the areas under the curves were integrated by Gaussian deconvolution of the peaks and the acidity was expressed as micromoles of ammonia per gram of catalyst.

\subsection{Evaluation of Catalytic Activity}

The catalytic cracking of residual palm oil in SBE was investigated using a reactor as shown in Figure 1. Firstly, about $100 \mathrm{~g}$ of SBE was heated from room temperature to $500{ }^{\circ} \mathrm{C}$ with an electric ceramic furnace to vaporize the organic compound in SBE. Then the volatile or-

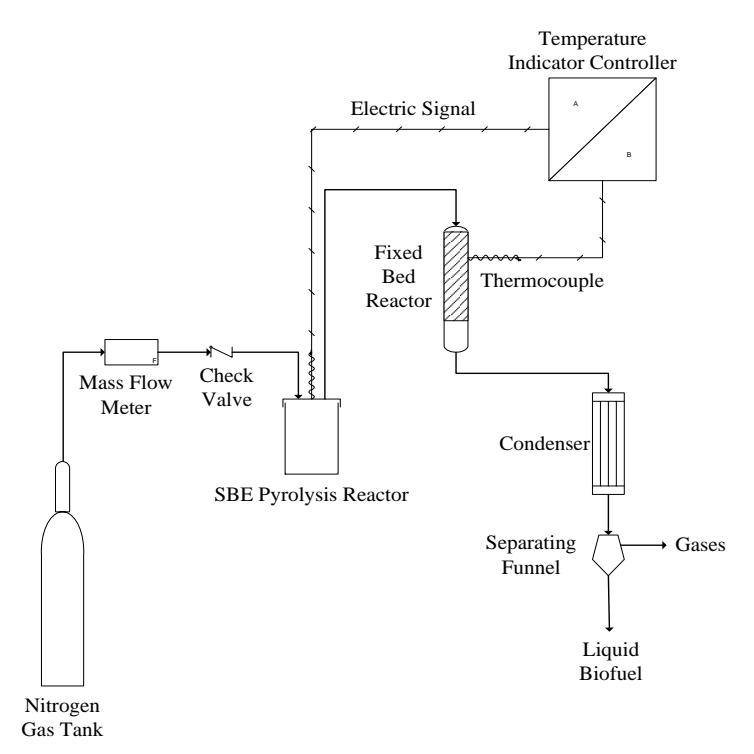

Figure 1. Schematic diagrams of catalytic cracking for the SBE 
ganic compounds pass through the catalytic bed at $450{ }^{\circ} \mathrm{C}$ atmospheric pressure under nitrogen gas flow $100 \mathrm{~mL} / \mathrm{min}$. About $0.2 \mathrm{~g}$ of catalyst was used for each run. The volatile products evolved from the reactor are passed through the condenser to collect the organic liquid product. The pyrolytic oil obtained was dissolved in dichloromethane and analyzed by GC-MS.

\subsection{Liquid Product Analysis using GC-MS}

PerkinElmer GC-MS $6890 \mathrm{~N}$ equipped with Elite $-5 \mathrm{MS}(30.0 \mathrm{~m} \times 0.25 \mathrm{~mm} \times 0.25 \mu \mathrm{m})$ was used for compound identification. Helium was employed as carrier gas at a constant flow rate of $1.5 \mathrm{~mL} \cdot \mathrm{min}^{-1}$. Initial oven temperature was set at $40^{\circ} \mathrm{C}$, held for $5 \mathrm{~min}$, ramped at $5{ }^{\circ} \mathrm{C}$ $\min ^{-1}$ to $300{ }^{\circ} \mathrm{C}$ and held for further $10 \mathrm{~min}$ with heated capillary transfer line maintained at $300{ }^{\circ} \mathrm{C}$. Splitless injection was carried out at $300{ }^{\circ} \mathrm{C}$ and $1.0 \mu \mathrm{L}$ of the sample was injected. Chromatographic peaks were identified with NIST mass spectral data library and the retention times were compared with standard compounds listed in Wiley Registry of Mass Spectral Spectral Data $8^{\text {th }}$ Edition and NIST 2008 Mass Spectral Libraries V2.2.

\section{Results and Discussion}

\subsection{Thermogravimetric (TGA) Analysis}

Thermogravimetric (TGA) analysis was used to investigate the thermal decomposition of SBE. Thermogram of SBE (Figure 2) showed four weight loss rates display four peaks at about $70,210,320$, and $730^{\circ} \mathrm{C}$. The first endothermic weight loss between 40 and $100{ }^{\circ} \mathrm{C}$ is due to the removal of adsorbed water molecules and chemically bonded $\mathrm{OH}^{-}$groups [14]. The second step weight loss in the temperature range of $170-240{ }^{\circ} \mathrm{C}$ is mainly associated to the decomposition of the organic content of the samples (evolution of volatile products or oils). The third step at the temperature between 260 and $360^{\circ} \mathrm{C}$ showing a major endothermic indicates carbonization of residual oils [13]. The fourth endothermic weight loss in the temperature range of $660-780{ }^{\circ} \mathrm{C}$ is due to the loss of structural hydroxyl groups in silica ( $\mathrm{Si}-\mathrm{OH}$ ) bonding released from different positions of the montmorillonite structure. Based on these results, the pyrolysis temperature at about 500 ${ }^{\circ} \mathrm{C}$ can be considered as the maximum operating temperature for pyrolysis of SBE under an inert atmosphere.

\subsection{X-Ray Diffraction (XRD) Analysis}

$\mathrm{X}$-Ray diffraction (XRD) analysis is used to determine the crystallinity of the developed catalysts. Figure 3 shows the XRD pattern of HZSM-5 at different metals loading. The XRD pattern of the modified zeolite indicates that the structure of the zeolites remains intact after loading different metals over the HZSM-5 catalyst. No new peaks related to the metals were found from the diffractograms in comparison to the XRD pattern of the HZSM-5 standard sample. These patterns reveal that the

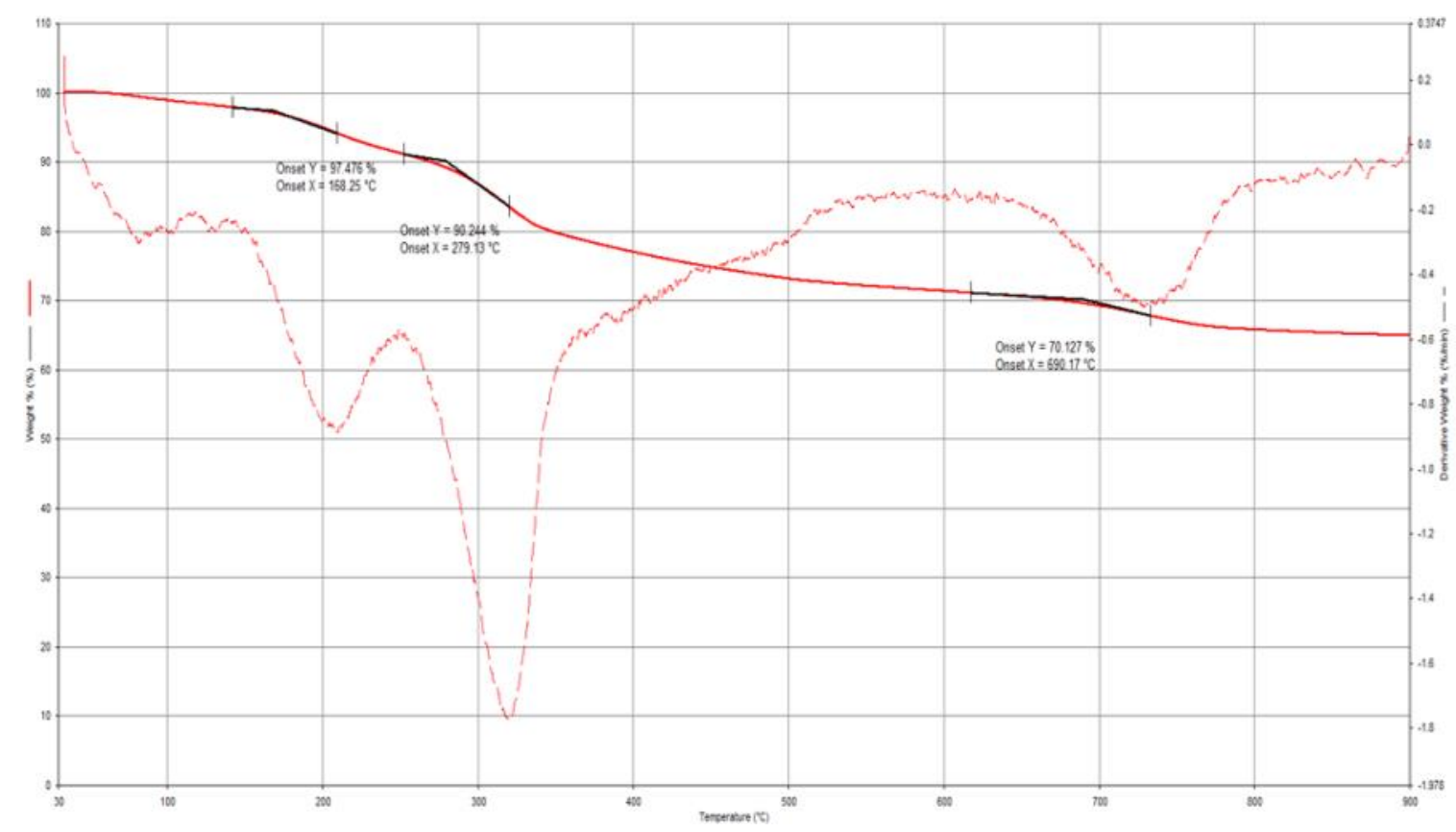

Figure 2. Thermogravimetry curves of SBE under heating rate of $10{ }^{\circ} \mathrm{C} \mathrm{min}-1$ 
metals were highly dispersed on the HZSM-5 catalyst for each of the metal-loaded catalyst [15].

\subsection{Fourier Transformed Infrared (FTIR)} Analysis

Fourier Transformed Infrared (FTIR) was used to analyze the presence of functional groups in catalyst. Figure 4 shows the spectra obtained from difference metals impregnated on HZSM- 5 catalyst. Generally, FTIR spectra showed that the metals impregnated has no apparent changes in the characteristic of HZSM-5 catalyst. From Figure 4, it can be observed that there were no significant band position shifts, hence no isomorphous substitution in HZSM-5 framework took place. This supports the prior discussion on XRD analysis that the HZSM-5 framework had remained intact.

Figure 4 revealed the significant peaks at around $3640 \mathrm{~cm}^{-1}, 3440 \mathrm{~cm}^{-1}, 1630 \mathrm{~cm}^{-1}$, $1220 \mathrm{~cm}^{-1}, 1090 \mathrm{~cm}^{-1}$, and $795 \mathrm{~cm}^{-1}$ corresponded to HZSM-5 vibration peaks. It is normal all the catalyst samples to exhibit $\mathrm{O}-\mathrm{H}$ group at the band near $3620 \mathrm{~cm}^{-1}$ band. The range is mainly attributed to the stretching or bending vibration of framework bridged hydroxyl groups (Al$\mathrm{OH}-\mathrm{Si}$ ). These findings are consistent with the results reported by Zakaria et al. [15]. However, the intensity of the band was not significant which might be due to the drying effect on all samples prior FTIR characterization. Other than that, all the modified catalysts show the peak monitored at around $1630 \mathrm{~cm}^{-1}$ which indicated that the adsorbed $\mathrm{H}_{2} \mathrm{O}$ might be presented in the modified HZSM-5 catalyst sample. The presence of $\mathrm{H}_{2} \mathrm{O}$ might occur during

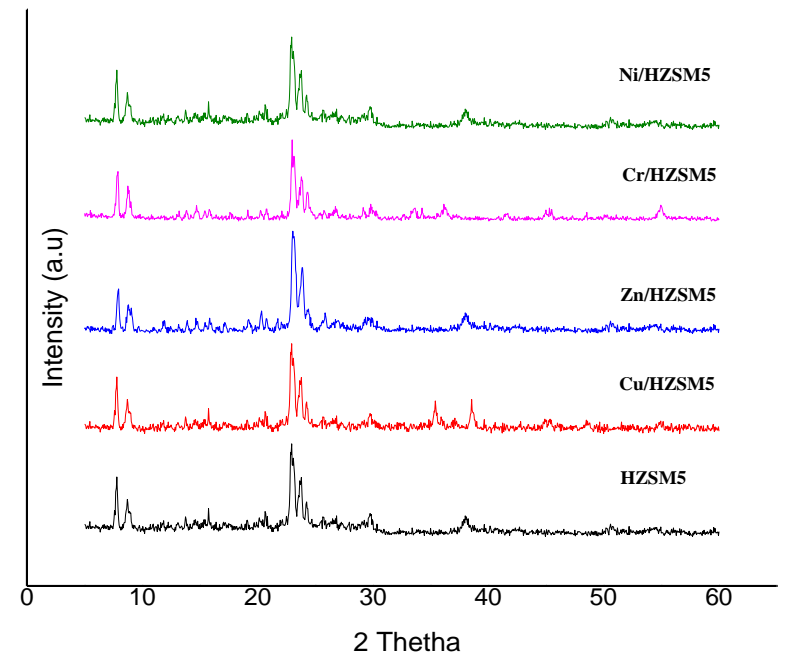

Figure 3. XRD spectra for various impregnated metal HZSM-5 catalysts the incipient wet impregnation process [16].

Another set of peaks can be observed at around $1220 \mathrm{~cm}^{-1}, 1090 \mathrm{~cm}^{-1}$, and $795 \mathrm{~cm}^{-1}$ which are associated with the asymmetric stretching vibrations of the $\mathrm{Si}-\mathrm{O}-\mathrm{Si}$. These bands are related to the internal linkages in $\mathrm{SiO}_{4}$ or $\mathrm{AlO}_{4}$ of the HZSM-5 lattices [17]. The double ring vibration band between 600-400 $\mathrm{cm}^{-1}$ was present for all metal modified on HZSM-5 catalyst. It indicates that the metal impregnated HZSM-5 catalyst had still a structure similar to HZSM-5. Similar observations were reported by Zakaria et al. [15].

\subsection{Nitrogen Adsorption-Desorption Analysis}

The results of BET from nitrogen adsorption-desorption analysis for all catalysts are presented in Table 1 alongside with TPD- $\mathrm{NH}_{3}$ results. As expected, it can be observed that HZSM-5 has the highest surface area compared to the others thus contributed to the surface area of $424.65 \mathrm{~m}^{2} \cdot \mathrm{g}^{-1}$. The surface area of Cu/HZSM-5 and Ni/HZSM-5 recorded was 288.5 and $287.35 \mathrm{~m}^{2} \mathrm{~g}^{-1}$, respectively in which is almost similar to that reported by Zakaria et al. [15]. In general, metal loading has significantly reduced the surface area, and pore volume of the parent HZSM-5 zeolite by at least $20 \%$. Interestingly, it was found that the micropore volume of Zn/HZSM-5 slightly higher from others but it still considers in acceptable value since the difference between HZSM- 5 and $\mathrm{Zn} / \mathrm{HZSM}-5$ is very small which only about $7.5 \%$ different. This mainly due to the increase in the number of micropores during the impregnation process [11]. Based on the decreasing trend in BET surface area and micro-pore

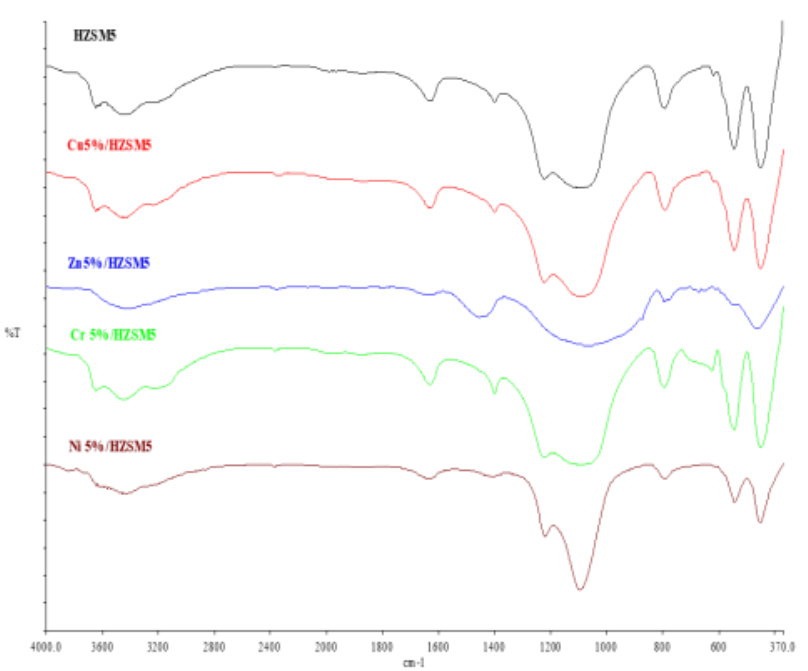

Figure 4. Fourier Transform Infra-Red (FTIR) for various impregnated metal ZSM-5 catalysts 
volume of the parent HZSM-5 catalyst, it can be deduced that the addition of metallic elements, such as: $\mathrm{Cu}, \mathrm{Zn}, \mathrm{Cr}$, and $\mathrm{Ni}$, might have produced a partial blockage effect towards zeolite channel. Similar observation was reported by Maia et al. [18].

\subsection{Temperature Program Desorption of Am-} monia (TPD- $\mathrm{NH}_{3}$ ) Analysis

TPD was carried out to evaluate the acidic properties of the catalysts towards the percentage of biofuel production. Figure 5 illustrates TPD- $\mathrm{NH}_{3}$ profiles obtained from the each catalyst. Several desorption peaks existed in all catalysts. Normally, strength of solid acid sites within TPD profiles can be classified by the temperature of desorption of $\mathrm{NH}_{3}$ as weak (120$\left.300{ }^{\circ} \mathrm{C}\right)$, moderate $\left(300-500{ }^{\circ} \mathrm{C}\right)$ and strong $(500$ $\left.650^{\circ} \mathrm{C}\right)$ [19].

From Figure 5, it can be observed that all the curves displayed a major desorption peak between $200{ }^{\circ} \mathrm{C}$ and $300{ }^{\circ} \mathrm{C}$, an indication of the weak sites present in the catalysts, which is consistent with typical HZSM-5 peak. This range of peak corresponds to weak acid sites from surface hydroxyl groups [20]. The concentration of these sites was deemed to be not catalytically important, but it is assumed to effectively influence the proton mobility in HZSM-5 [21]. A second desorption peak was obtained for HZSM-5, Cu/HZSM-5 and Ni/HZSM5 in the range of $300-400{ }^{\circ} \mathrm{C}$, indicating the presence of moderate acid sites but there is no obvious peak was observed for Zn/HZSM-5 and Cr/HZSM- 5 at this point. According to Murata et al. [22], the peak between 350 and $450{ }^{\circ} \mathrm{C}$ is closely related to surface acid properties. In the range of $450-550{ }^{\circ} \mathrm{C}$ the amount of acid sites for Cu/HZSM-5 was found the highest followed closely by Ni/ZSM-5 and at this point there is no peak was observe for HZSM-5, Zn/HZSM-5, and $\mathrm{Cr} / \mathrm{HZSM}-5$.

From the TPD-ammonia test, it can be inferred that the impregnation of metal induces new weak, moderate and strong acid sites differently. The surface acidity was calculated as total acidity and expressed per mmol of $\mathrm{NH}_{3}$ desorbed per gram of catalyst, between 100 and $650{ }^{\circ} \mathrm{C}$ [15]. The various acidic properties of catalysts are caused by the availability of crystallographically with different sittings and framework atoms dwelling in diverse environment [23]. Table 1 showed the total acidity of each catalyst. It can be observed that $\mathrm{Cu} / \mathrm{HZSM}-5$ has the highest total acidity followed by Ni/HZSM- 5 . These results showed that the introduction of metallic on HZSM-5 has greatly influenced the acidity of the catalyst.

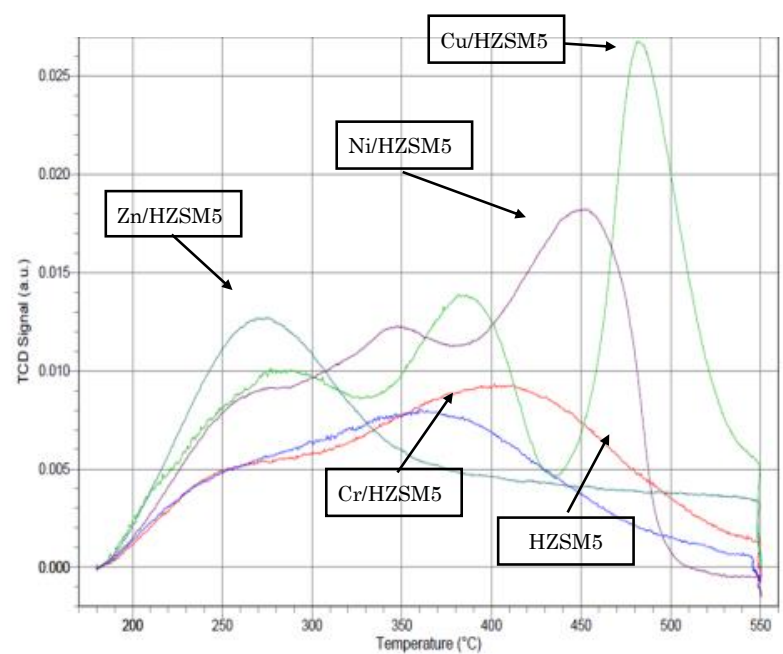

Figure 5. Temperature program desorption ammonia (TPD-NH 3 ) profiles for HZSM-5 and modified ZSM-5 catalysts

Table 1. Nitrogen adsorption-desorption and TPD- $\mathrm{NH}_{3}$ method of catalysts

\begin{tabular}{ccccccc}
\hline Catalysts & \multirow{2}{*}{$\begin{array}{c}\text { Surface } \\
\text { area } \\
\left(\mathrm{m}^{2} / \mathrm{g}\right)^{\mathrm{a}}\end{array}$} & $\begin{array}{c}\text { Micro pore } \\
\text { volume } \\
\left(\mathrm{cm}^{3} / \mathrm{g}\right)^{\mathrm{b}}\end{array}$ & $\begin{array}{c}\text { Total of acidity, } \\
(\mathrm{mmol} / \mathrm{g})^{\mathrm{c}}\end{array}$ & \multicolumn{2}{c}{ Distribution of acid sites } \\
\cline { 6 - 7 } HZSM-5 & 424.6482 & 0.1795 & 0.71973 & 0.20627 & 0.51346 & - \\
Cu/HZSM-5 & 288.5371 & 0.1730 & 1.5935 & 0.91441 & 0.16785 & 0.51124 \\
Zn/HZSM-5 & 293.1967 & 0.1929 & 0.82165 & 0.82165 & - & - \\
Cr/HZSM-5 & 337.0244 & 0.1620 & 0.61454 & 0.61454 & - & - \\
Ni/HZSM-5 & 287.3484 & 0.1590 & 1.24353 & 0.42211 & 0.08463 & 0.73679 \\
\hline
\end{tabular}

a Obtain from BET method.

b Obtained from BJH method.

c Obtained from TPD- $\mathrm{NH}_{3}$ analysis. 


\subsection{Liquid Product Analysis}

Figure 6 provides the overall information about the area \% of hydrocarbon group obtained in catalytic cracking of oil in spent bleaching earth (SBE). Approximately, 8.0-11.0 wt. \% of the pyrolytic oil was obtained from 100 $\mathrm{g}$ of SBE catalytic cracking. The catalytic cracking is a complex mixture made up of hundreds of organic compounds from a wide variety of chemical groups. The compounds identified in the cracking oil have been grouped into classes of compounds, such as: mono aromatic compounds, alkenes, alkanes, alcohols, ketones, aldehydes, carboxylic acids, esters, nitrogenated compounds, and polycyclic aromatic hydrocarbons (PAHs).

Carboxylic acids were found to be the major group of compounds present followed by ester group. The compounds found were similar to the pyrolytic oil compounds reported in previous studies [3]. As previously reported, triglyceride composition of the crude palm oil and residual oil in the bleaching earth is similar [26, 27]. The main triglycerides of fatty acid profile were palmitic acid, or hexadecanoic acid (44.8 $\%$ ), oleic acid, or cis-9-octadecenoic acid (38.6 $\%)$, and linoleic acid, or cis-9,12-octadecadienoic acid (10.6\%). From this result, it shows that the main residue palm oil composition in SBE that containing the long chain heavy fraction of triglyceride fatty acid, such as: palmitic acid, oleic acid, and linonelic acid, have been cracked into several short chain molecules. These results indicated that the metal loaded on HZSM-5 can promote the cracking of heavy fractions contained in SBE to lighter hydrocarbons.

According to Ong and Bhatia [24], palm oil first undergoes thermal and catalytic cracking on the external surface of catalysts to produce heavy hydrocarbons and oxygenates then these products were further cracked into light alkenes and alkanes, water, carbon dioxide, and carbon monoxide. They also suggested that primary cracking occurs within the internal pore structure of zeolite catalysts. Furthermore, the palm oil containing triglycerides with long chain fatty acids were converted into short chain molecules by deoxygenation, cracking, oligomerization, alkylation, isomerization, and aromatization [24].

Figure 7 shows the comparison production of alkenes and alkanes for these modified metal loaded on HZSM-5. It shows that the liquid products of alkenes and alkanes were increases compared to non-catalytic and parent HZSM-5 when metallic was introduced to HZSM-5 catalyst. The liquid product for Ni/ZSM-5 produce the highest alkenes of area $\%$ which is 4.14 area \% followed by Cr/ZSM- 5 of

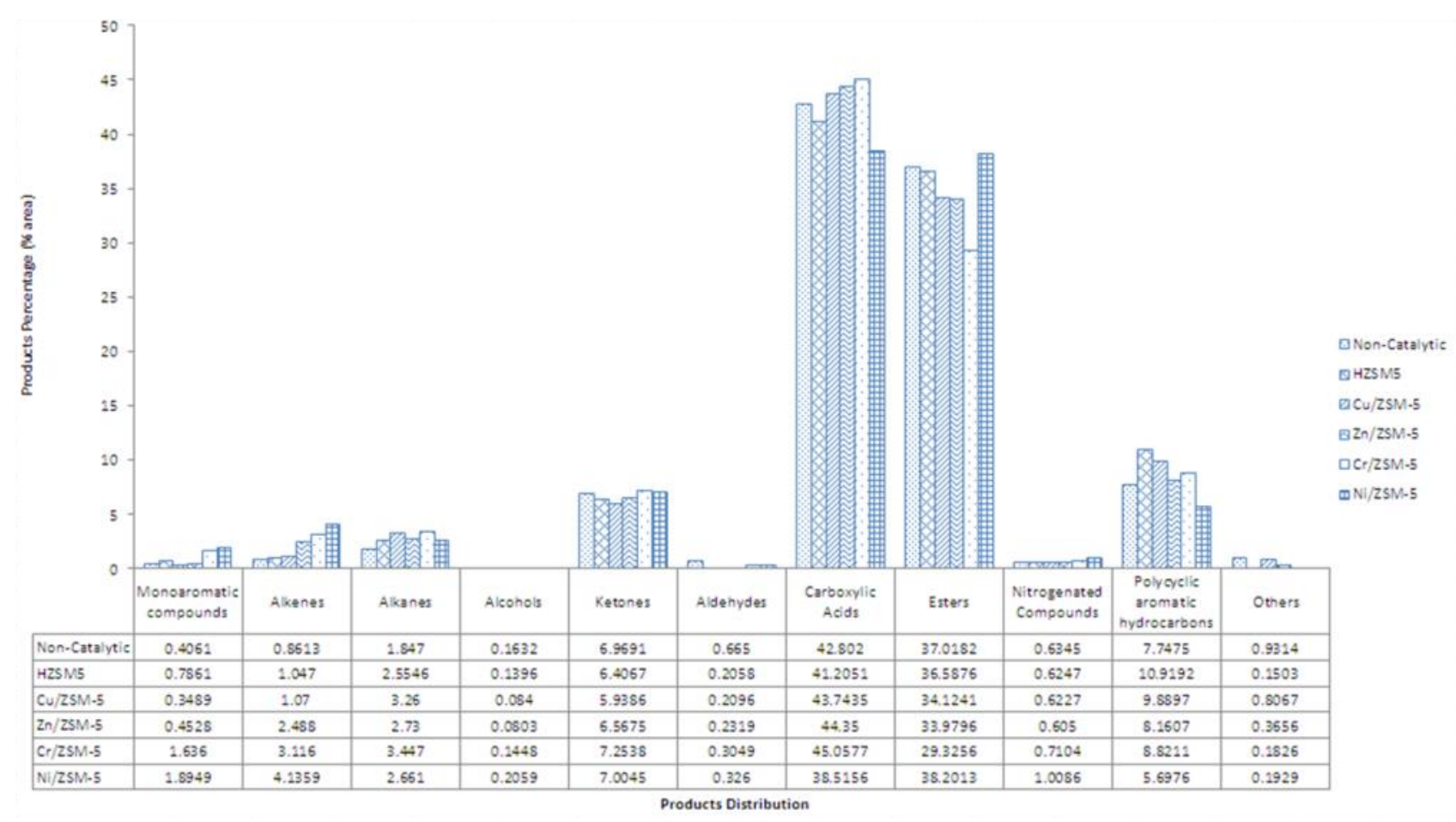

Figure 6. Identification compounds (\% area) from GC-MS analysis of the catalytic cracking of spent bleaching earth (SBE) and with different metal incorporated in HZSM-5 zeolite based catalyst (distribution by hydrocarbon groups) 
3.12 area $\%, \mathrm{Zn} / \mathrm{ZSM}-5$ of 2.49 area $\%, \mathrm{Cu} / \mathrm{ZSM}$ 5 of 1.07 area \%, HZSM-5 of 1.05 area \%, and non-catalytic of $0.861 \%$. These results indicated that the incorporation of metal over HZSM-5 zeolite promotes the cracking activity of HZSM-5 zeolite. Nickel doped HZSM-5 has good catalytic behavior due to its changes in total acid sites as compared to parent zeolite. The similar observation was reported by Maia et al. [18] in the catalytic activity of Ni-ZSM-5 zeolites in the isobutane and $n$-butane cracking reaction. They found that the increasing percentage Ni doped in HZSM-5 leads the increasing in molar ratio of alkenes/alkanes in isobutane catalytic cracking as compare to parent HZSM-5 zeolite. They also suggest that the dehydrogenation products formed at the nickel sites sequentially reacted on acidic sites. This clearly indicated that Ni loaded on the HZSM-5 zeolite strongly promotes cracking of heavy fractions, leading to formation of lighter fractions [25]. Cr/ZSM-5 produce the highest alkanes compare to other in the following order which is 3.45 area \% followed by Cu/ZSM-5 of 3.26 area \%, Zn/ZSM-5 of 2.73 area \%, Ni/ZSM-5 of 2.66 area \%, HZSM-5 of 2.55 area $\%$ and non-catalytic of 1.85 area \%. The increasing in alkenes and alkanes area \% may be due to the changes in total acid sites and surface area as compared to parent zeolite. The total acid sites may originate from the physical changes on the catalyst surface (as a result of metal loading) and resulted to formation of new several weak, moderate and strong acid sites [15].

Figure 8 focused on the area \% of monoaromatic and polycyclic aromatic compounds. The liquid products contain the highest monoaromatic was Ni/ZSM-5 which is $1.89 \%$, Cr/ZSM-5 of 1.64 area \%, HZSM-5 of 0.79 area

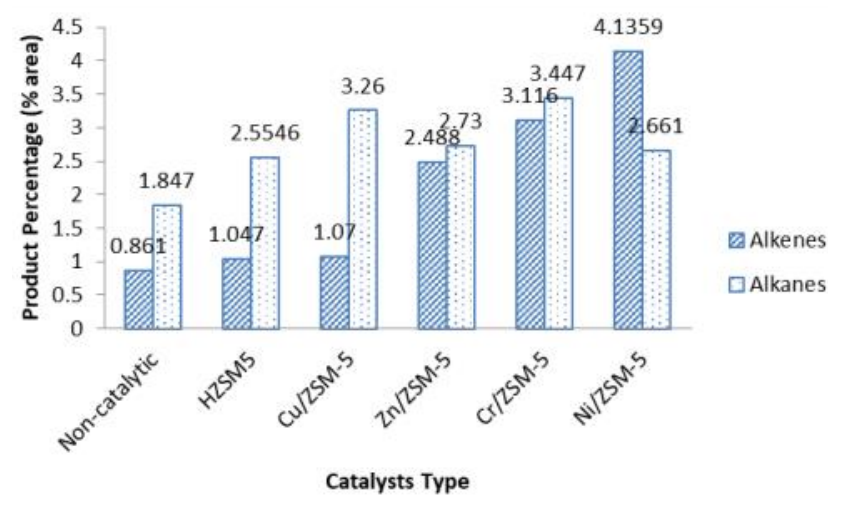

Figure 7. Alkenes and alkanes compound percentage area with different metal incorporated in HZSM-5 zeolite based catalyst
$\%, \mathrm{Zn} / \mathrm{ZSM}-5$ of 0.45 area $\%$, non-catalytic of 0.41 area $\%$ and Cu/ZSM-5 of 0.35 area \%, respectively. The impregnation of HZSM-5 catalyst with nickel and chromium strongly increases the production of mono-aromatics, roughly twice as much as that on the parent HZSM-5 zeolite. These results indicated that the Ni/HZSM-5 exhibited hydrogenation and ring opening of poly-aromatics, which transforms poly-aromatics to mono-aromatics. Furthermore, the introduction of nickel on HZSM-5 zeolite might promote the cyclization and dehydrogenation of olefins and aromatization of naphthenes, leading to the high formation of mono-aromatics [25]. The area \% of polycyclic aromatic hydrocarbons (PAHs) for the parent HZSM-5 increase compared to noncatalytic and other metal loaded on the HZSM-5 zeolite. The area \% of liquid product collected from HZSM-5 catalyst produce the highest PAHs of area \% which is 10.92 area \%. The liquid product containing PAHs for Cu/ZSM-5 of 9.89 area \%, Cr/ZSM-5 of 8.82 area $\%, \mathrm{Zn} / \mathrm{ZSM}-5$ of 8.16 area $\%$, non-catalytic of 7.75 area \%, and Ni/ZSM-5 of 5.70 area \% also detected. Katikaneni et al. [28] stated that aromatic hydrocarbons were produced through oligomerization, acid catalyzed cyclization, and $\mathrm{H}$-transfer reactions on hydrocarbon molecules.

\section{Conclusions}

The liquid product obtained from catalytic cracking from palm oil in SBE show that the palm oil in SBE with long chain fatty acids can be converted into short chain molecules. It is proved that the several groups of compounds were identified in the cracking oil, such as: monoaromatic compounds, alkenes, alkanes, alcohols, ketones, aldehydes, carboxylic acids,

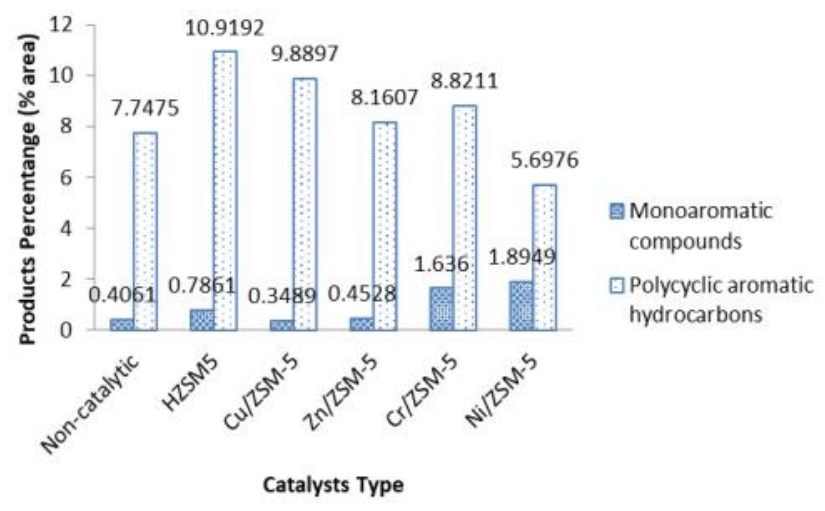

Figure 8. Mono aromatic and polycyclic aromatic compounds percentage area with different metal incorporated in HZSM-5 zeolite based catalyst 
esters, nitrogenated compounds and polycyclic aromatic hydrocarbons (PAHs). Metal loaded on HZSM-5 zeolite can be considered an interesting catalyst for the improvement of the quality of biofuel from residual palm oil in SBE via catalytic cracking to lighter hydrocarbons. The results indicated that the incorporation of metal such as cuprum, zinc, chromium, and nickel over HZSM-5 zeolite was strongly promoted the production of alkanes and alkenes, indicating that with metal loading the cracking activity of catalyst highly increased. Cr/ZSM-5 and Ni/ZSM-5 favored the conversion of polycyclic aromatics to mono-aromatics, whereas parent HZSM-5 catalyst favored the formation of poly-aromatics. These results indicated that the surface area and acidity of HZSM-5 can promote the cracking of heavy fractions. It is reasonable to conclude that metal loaded on HZSM-5 has the ability on improving and enhance the petrochemical production from catalytic conversion of residual palm oil in spent bleaching earth (SBE).

\section{Acknowledgement}

The authors gratefully acknowledge the financial supports from Ministry of Education and from Vote $13 \mathrm{H} 36$ (GUP) Universiti Teknologi Malaysia for the technical and materials support.

\section{References}

[1] Taylor, D.R., Jenkins, D.B., (1990). Factors Affecting the Pyrophorisity of Spent Bleaching Clay. J. Am. Oil Chem. Soc., 67: 678.

[2] Suhartini, S., Hidayat, N., Wijaya, S. (2011). Physical Properties Characterization of Fuel Briquette Made from Spent Bleaching Earth. Biomass and Bioenergy, 35: 4209-4214.

[3] Boey, P.L., Saleha, M.I., Sapawea, N., Ganesana, S.,Maniama, G.P., Mohamed Hag Ali, D. (2011). Pyrolysis of Residual Palm Oil in Spent Bleaching Clay by Modified Tubular Furnace and Analysis of the Products by GCMS. Journal of Analytical and Applied Pyrolysis, 91: 199-204.

[4] Prajitno, D.H., Roesyadi, A., Al-Muttaqii, M., Marlinda, L. (2017). Hydrocracking of Nonedible Vegetable Oils with Co-Ni/HZSM-5 Catalyst to Gasoil Containing Aromatics. Bulletin of Chemical Reaction Engineering \& Catalysis. 12(3): 318-328.

[5] Maher, K.D., Bressler, D.C. (2007). Pyrolysis of Triglyceride Materials for the Production of Renewable Fuels and Chemicals. Bioresource Technology, 98:2351-2368
[6] Adjaye, J.D., Bakhshi, N.N. (1995). Production of Hydrocarbons by Catalytic Upgrading Of a Fast Pyrolysis Bio-Oil. Part I: Conversion over Various Catalysts. Fuel Process. Technol., 45:161-183.

[7] Zhang, Q., Chang, J., Wang, T.J., Xu, Y. (2007). Review of Biomass Pyrolysis Oil Properties and Upgrading Research. Energy Convers. Manage., 48: 87-92.

[8] Williams, P.T., Nugranad, N. (2000). Comparison of Products from the Pyrolysis and Catalytic Pyrolysis of Rice Husks. Energy, 25: 493-513.

[9] Taufiqurrahmi, N., Mohamed, A.R., Bhatia, S. (2007). Production of Biofuel from Waste Cooking Palm Oil using Nanocrystalline Zeolite as Catalyst: Process Optimization Studies. Bioresource Technology, 102: 1068610694.

[10] Botas, J.A., Serrano, D.P., Garcíac, A., Vicentea, J.D., Ramosa, R. (2012). Catalytic Conversion of Rapeseed Oil into Raw Chemicals and Fuels Over Ni- and Mo-modified nanocrystalline ZSM-5 zeolite, Catalysis Today. 195: 59-79

[11] Rahimi and R. Karimzadeh (2011). Catalytic Cracking of Hydrocarbons over Modified ZSM-5 Zeolites to Produce Light Olefins: $A$ Review Applied Catalysis A: General, 398: 117.

[12] Roesyadi, A., Hariprajitno, D., Nurjannah, N., Savitri, S.D. (2013). HZSM-5 Catalyst for Cracking Palm Oil to Gasoline: A Comparative Study with and without Impregnation. Bulletin of Chemical Reaction Engineering \& Catalysis, 7 (3): 185-190.

[13] Tsai, W.T., Chen, H.P., Hsieh, M.F., Sun, H.F., Chain, S.F. (2002). Regeneration of Spent Bleaching Earth by Pyrolysis in A Rotary Furnace. J. Anal. Appl. Pyrol., 63: 157170.

[14] Mana, M., Ouali, M.S., De Menorval. L.C. (2007). Removal of Basic Dyes from Aqueous Solutions with a Treated Spent Bleaching Earth. J. Colloid Interface Sci., 307: 9-16.

[15] Zakaria, Z.Y., Linnekoski, J.,S. Amin, N.A. (2012). Catalyst Screening for Conversion of Glycerol to Light Olefins. Chemical Engineering Journal, 207-208: 803-813.

[16] Zhao, X., Wei, L., Julson, J., Qiao, Q., Dubey, A., Anderson, G. (2015). Catalytic Cracking of Non-Edible Sunflower Oil over ZSM-5 for Hydrocarbon Bio-Jet Fuel. New Biotechnology, 32: 2 .

[17] Jiang Y.J., Juan J.C., Meng X.J., Cao W.L., Yarmo M.A., Zhang J.C. (2007). Preparation and Catalytic Application of Novel Water Tolerant Solid Acid Catalysts of Zirconium 
Sulfate/HZSM-5. Chemical Research in Chinese Universities. 23: 349-354.

[18] Maia A.J., Louis B., Lam Y.L., Pereira M.M. (2010). Ni-ZSM-5 catalysts: Detailed Characterization of Metal Sites for Proper Catalyst Design. Journal of Catalysis, 269(1): 103-109.

[19] Suprun, W., Lutecki, M., Haber, T., Papp, H. (2009). Acidic Catalysts for the Dehydration of Glycerol: Activity and Deactivation. J. Mol. Catal., A: Chem. 309: 71-78.

[20] Rodríguez-González, L., Hermes, F. Bertmer, M., Rodríguez-Castellón, E., Jiménez-López, A. Simon, U. (2007).The Acid Properties of HZSM-5 as Studied by $\mathrm{NH}_{3}$-TPD and 27AlMAS-NMR Spectroscopy. Appl. Catal. A: Gen., 328: 174-182.

[21] Franke, M.E., Simon, U. (2004). Solvatesupported proton transport in zeolites. ChemPhysChem, 5: 465-472.

[22] Murata, K., Takahara, I. Inaba, M. (2008). Propane Formation by Aqueous-Phase Reforming of Glycerol over Pt/H-ZSM5 Catalysts. React. Kinet. Catal. Lett., 93: 59-66.

[23] Damjanovic', L., Auroux, A. (2010). Determination of Acid/Base Properties by Temperature Programmed Desorption (TPD) and Adsorption Calorimetry Zeolite Characterization and Catalysis, in: A.W. Chester, E.G. Derouane (Eds.), Springer, Netherlands, pp. 107-167.
[24] Ong, Y.K., Bhatia S. (2010). The Current Status and Perspectives of Biofuel Production via Catalytic Cracking of Edible and Non-Edible Oils, Energy. 35: 111-119.

[25] Namchot, W., Jitkarnka S. (2015). Upgrading Of Waste Tyre-Derived Oil from Waste Tyre Pyrolysis Over Ni Catalyst Supported On HZSM-5 Zeolite. Chemical Engineering Transactions, 45: 775-780.

[26] Huang, Y.P., Chang, J.I. (2010). Biodiesel Production from Residual Oils Recovered from Spent Bleaching Earth. Renewable Energy. 35: 269-274

[27] Pizarrro, A.V.L., Park, E.Y. (2003). LipaseCatalyzed Production of Biodiesel Fuel From Vegetable Oil Contained in Waste Activated Bleaching Earth. Process Biochem. 38: 107782.

[28] Katikaneni S.P.R., Adjaye J.D., Bakhshi N.N. (1995). Catalytic Conversion of Canola Oil to Fuels and Chemicals over Various Cracking Catalysts. Can. J. Chem. Eng., 73: 484-497. 